\title{
Trends in hypertension prevalence, awareness, treatment, and control among Polish adults 75 years and older during 2007-2014
}

\author{
Arkadiusz A. Niklas ${ }^{1}$, Anna Flotyńska ${ }^{1}$, Tomasz Zdrojewski², Andrzej Pająk ${ }^{3}$, \\ Roman Topór-Mądry ${ }^{3}$, Paweł Nadrowski ${ }^{4}$, Maria Polakowska ${ }^{5}$, \\ Magdalena Kwaśniewska ${ }^{6}$, Aleksandra Puch-Walczak ${ }^{2}$, Wojciech Bielecki ${ }^{6}$, \\ Krystyna Kozakiewicz ${ }^{4}$, Wojciech Drygas ${ }^{5}$, Andrzej Tykarski ${ }^{1}$; \\ on behalf of WOBASZ II investigators*
}

\begin{abstract}
${ }^{1}$ Department of Hypertension, Angiology and Internal Disease, University of Medical Science, Poznan, Poland; ${ }^{2}$ Department of Arterial Hypertension and Diabetology, Medical University of Gdansk, Poland; ${ }^{3}$ Chair of Epidemiology and Population Studies, Institute of Public Health, Faculty of Health Sciences, Jagiellonian University Medical College, Krakow, Poland; ${ }^{4} 3^{\text {rd }}$ Department of Cardiology, Medical University of Silesia, Katowice, Poland; ${ }^{5}$ Department of Epidemiology, Cardiovascular Disease Prevention and Health Promotion, Institute of Cardiology, Warsaw, Poland; ${ }^{6}$ Department of Social and Preventive Medicine, Medical University of Lodz, Poland
\end{abstract}

\begin{abstract}
Background: The aim of this study was to assess changes in the prevalence, awareness, and treatment of hypertension and its effectiveness between 2007 (WOBASZ Senior study) and 2013-2014 (WOBASZ II) in a sample of the Polish population over the age of 75 years.

Methods: Sampling had three stages, stratified according to voivodeships, type of community, and gender. Finally, the WOBASZ II study included 467 persons (290 women and 177 men). For a comparison of the data, 1096 persons (538 women and 554 men) examined in the WOBASZ Senior study were used. Results: Systolic and diastolic blood pressures significantly decreased from $153.0 \pm 23.9 \mathrm{mmHg}$ to $142.9 \pm 22.3 \mathrm{mmHg}$ and from $85.2 \pm 11.9 \mathrm{mmHg}$ to $78.4 \pm 11.3 \mathrm{mmHg}$, respectively, from 2007 to 2014 $(p<0.0001)$. Prevalence of hypertension among people included in WOBASZ studies slightly decreased from $83.8 \%$ to $77.9 \%$ (rate ratio [RR]: 0.95; 95\% confidence interval [CI]: 0.78-1.16) in men, and from $75.4 \%$ to $71.8 \%$ (RR: 0.93; 95\% CI: 0.8-1.09) in women. Hypertension awareness was improved from $59.2 \%$ to $72.9 \%$ (RR: 1.23; 95\% CI: 0.97-1.56) in men, and from 74,8\% to 93\% (RR: 1.26 ; $95 \% \mathrm{CI}$ : 1.01-1.58) in women. The proportion of men and women, with implemented hypertension treatment, increased from $48.4 \%$ to $61.1 \%$ (RR: 1.26; 95\% CI: 1.01-1.58), and from $63.2 \%$ to $82.0 \%$ (RR: 1.3; 95\% CI: 1.1-1.53), respectively. The effectiveness of the treatment was improved over two-fold, there was an increase from $10.3 \%$ to $26.8 \%$ (RR: 2.65; 95\% CI: 1.81-3.89) in men, and from $13.8 \%$ to $33.5 \%$ in women (RR: 2.44; 95\% CI: 1.81-3.3).

Conclusions: The prevalence of hypertension in Polish seniors remains high, but has decreased slightly in the perspective of the last 7 years. Although treatment and control has improved over the last decade, it remains below expectations. Efforts to improve the diagnosis and effective treatment of hypertension in Polish seniors should be intensified. (Cardiol J 2018; 25, 3: 333-344)

Key words: elderly, health examination surveys, clinical epidemiology, prevalence of hypertension, awareness of hypertension, treatment of hypertension, control of hypertension
\end{abstract}

Address for correspondence: Dr. Arkadiusz Niklas, Department of Hypertension, Angiology and Internal Disease, ul. Dluga 1/2, 61-848 Poznań, Poland, tel/fax: +48 618549090, e-mail: aniklas@ump.edu.pl

Received: $13.02 .2018 \quad$ Accepted: 18.03 .2018

*A complete list of members in the Trial WOBASZ II is available at: Kardiologia Polska 2016; 74, 7: 681-690; doi: 10.5603/KP.a2015.0235. 


\section{Introduction}

Over a decade (from 2004 to 2014), the number of Europeans over 65 years of age has increased by more than $2 \%$. In 2014, the highest percentage of elderly residents (over 65 years old) was recorded in Italy $(21.4 \%)$, Germany $(20.8 \%)$ and the lowest being Ireland (12.6\%). In Poland it accounted to $14.9 \%$ [1]. Between 2007 and 2014, the number of Poles over the age of 75 increased from 2326423 to 2676211 , which represented $6.10 \%$ and $6.96 \%$ of the total population, respectively $[2,3]$. The number of residents over the age of 80 will double to more than 3.5 million by the year 2050 . The population of the over-80-year-olds in 2050 will constitute $10.4 \%$ of the population nationally, while in 2013 it was $3.9 \%$ [4]. In the general population in Poland, mortality due to cardiovascular diseases (CVD) in 2013 was approx. 46\%, 53\% of those people were over 65 years of age and over $80 \%$ were above the age of 80 [5]. Hypertension is one of the most important risk factors for CVD, such as a coronary heart disease, heart failure and stroke [6]. Hypertension treatment in patients at a very old age, significantly reduces the incidence of cardiovascular events and total mortality [7-9]. Epidemiological studies on CVD risk factors, including hypertension, in the elderly people are not frequent. Usually, an upper age limit in the examined populations was 74-79 years, or the data presented generally covered people over 65 years of age [10-14]. The WOBASZ study conducted in Poland in 2005 comprised a population below 75 years of age [15], while the NATPOL study completed in 2011 included respondents below 79 years of age [16]. Only one Polish study POLSENIOR conducted in 2007-2011 involved a population at the age of 65-104 years [17]. In the present study, the prevalence, awareness, treatment, and effectiveness of hypertension treatment in the Polish population aged 75-99 years in two Polish cross-sectional studies conducted in the years 2005-2007 and 2013-2014: WOBASZ Senior and using data for the age group of 75-99 years from WOBASZ II was examined. The changes are also described in systolic blood pressure (SBP) and diastolic blood pressure (DBP), as well as body mass index (BMI) and metabolic parameters such as the concentration of glucose, total cholesterol (TC), triglycerides (TG), low-density lipoprotein (LDL), high-density lipoprotein (HDL) in a very elderly Polish population.

\section{Methods}

\section{Study design}

Data from two studies were analyzed: WOBASZ Senior was carried out in 2007, which included 1096 subjects, and a subsample of 461 people over 74 years of age from the WOBASZ II study completed in 2013-2014 (WOBASZ Senior II). The assumptions and objectives of both projects as well as a detailed description of the respondents were described previously $[18,19]$. The methodology (study protocol, training materials, a set of questionnaires and instructions for each element of the study) was based on protocol of the first edition of WOBASZ [20] and European Union guidelines concerning the methodology of epidemiological studies of CVDs (EHES) [21]. The examined sample was randomly selected from the Polish population, at the Department of National Registers MIA (an electronic register - PESEL). The selection was made separately in each voivodeship. A schematic diagram of sampling was three-stage, stratified according to voivodeship, category of municipalities, and sex.

\section{Data collection and measurement}

The participants were stratified into the following three age groups: 75 to 79,80 to 84 , and 85 years. Subsequent to overnight fasting, blood specimens were obtained for the measurement of serum lipids and glucose, and the samples were sent to a central certified laboratory (Diagnostyka Sp. $z$ o.o., Warsaw, Poland) [19]. BMI was calculated as the ratio of weight $(\mathrm{kg})$ and height squared $(\mathrm{m})$. The following definitions were accepted:

- obesity - when BMI $\geq 30 \mathrm{~kg} / \mathrm{m}^{2}$;

- diabetes - when diagnosed previously or if the patient received hypoglycemic drugs;

- hyperlipidemia - when TC level exceeded 5.0 $\mathrm{mmol} / \mathrm{L}$ or cholesterol LDL exceed $3.0 \mathrm{mmol} / \mathrm{L}$ or if the patient received lipid-lowering drugs;

- coexisting CVD - previously diagnosed coronary artery disease, past myocardial infarction, myocardial revascularization, previous stroke, peripheral atherosclerosis;

- education - the participants were divided into two groups - less than 7 years of education or 7 years and more;

- physical activity - at least 30 min of uninterrupted activity, e.g.: a walk, gymnastic exercises at least once a month;

— smoking — at least one cigarette per day over the last year; 
- marital status - married or widow/widower, single.

\section{Blood pressure measurement and definitions}

Blood pressure (BP) measurements were performed as recommended by ESC/ESH 2013 [22]. Pressure measurements took place in one visit, in a quiet room in a sitting position with back propped. Participants did not drink coffee or smoke cigarettes for a minimum 30 min before measurement. Automatic devices approved by the Association for the Advancement of Medical Instrumentation (AAMI) were used for the measurements: AND UA-767 in WOBASZ Senior study, and AND UA-631 in WOBASZ II study (AND Company Limited, Tokyo, Japan). The measurement was performed 3 times at $1 \mathrm{~min}$ intervals on the right shoulder in a sitting position, after a 5 min rest. An average value from the second and third measurement was taken for pressure evaluation. If all three pressure measurements were not completed, a single measurement or an average of two measurements were taken into account.

According to the recommendations of the World Hypertension League Expert Committee [23], the following definitions were accepted:

- hypertension was calculated as the proportion of participants presenting $\mathrm{SBP} \geq 140 \mathrm{mmHg}$ or $\mathrm{DBP} \geq 90 \mathrm{mmHg}$ or reports currently (regular in last 2 weeks) treatment for high BP, to whole sample;

- proportion of awareness of hypertension was calculated as the proportion of participants with hypertension who report either being diagnosed with hypertension by a health professional or report taking medication for high $\mathrm{BP}$, to hypertensive patients; (affirmative response to the questions: "Have you ever been told by a doctor that you had hypertension, also called high blood pressure?" and "Have you ever taken medicine prescribed because of high blood pressure?";

- the proportion of treated hypertension was calculated as the proportion of participants with hypertension who report taking medication for high BP, to all hypertensive participants (affirmative response to the questions: "Have you taken this medicine regularly during the last 2 weeks?";

- proportion of controlled hypertension was calculated as the proportion of participants with hypertension, who both: reported taking medication for high $\mathrm{BP}$ and had SBP $<140$ $\mathrm{mmHg}$ and $\mathrm{DBP}<90 \mathrm{mmHg}$, to all hyperten- sive participants. Due to the fact that European and Polish guidelines allow in people over 80 years old an exception to the determined target pressure $(\mathrm{BP}<140 / 90 \mathrm{mmHg})$, additional calculations were made for the threshold of 150/90 mmHg.

The described BP categories (optimal, normal and high normal) concerned the whole population, including those treated. However, the same methodology in the presentation of results was adopted for a previous publication on the WOBASZ study. Owing to this the obtained results could be compared and evaluated for changes in the prevalence of raised BP in the Polish population.

The subjects were qualified for the optimal pressure group according to the recommendations of PTNT 2015 [19] and ESC/ESH 2013 [22], when $\mathrm{SBP}<120 \mathrm{mmHg}$ and DBP $<80 \mathrm{mmHg}$, for the normal pressure group when SBP was 120-129 $\mathrm{mmHg}$ and/or DBP 80-84 $\mathrm{mm} \mathrm{Hg}$ and for highnormal group, when SBP was 130-139 mmHg and/ /or DBP 85-89 mmHg. Grade 1 hypertension was diagnosed when SBP was 140-159 $\mathrm{mmHg}$ and/ /or DBP 90-99 mm Hg, grade 2 when SBP was $160-179 \mathrm{mmHg}$ and/or DBP $100-109 \mathrm{mmHg}$, grade 3 when SBP was $\geq 180 \mathrm{mmHg}$ and/or DBP $\geq 110$ $\mathrm{mmHg}$. Isolated systolic hypertension was diagnosed as $\mathrm{SBP} \geq 140 \mathrm{~mm} \mathrm{Hg}$ and $\mathrm{DBP}<90 \mathrm{mmHg}$.

\section{Statistical analysis}

All statistical tests were two-sided and statistical significance was accepted for $\mathrm{p}<0.05$. Parameters such as BP values were described using an arithmetic mean and standard deviation. Crude incidence of hypertension, awareness, frequency of treatment, BP control (as defined above) were described as percentages, with standard error and 95\% confidence interval (95\% CI) at the following age intervals: $75-79,80-84$ and over 85 years. The results were standardized [24] for age and sex of the Polish population on the basis of data from the report of the Central Statistical Office of 31.12.2014 (Suppl. Tables 1 and 2) [25].

The rate ratio (RR) with $95 \%$ CI was calculated, dividing the standardized frequency of above listed parameter in WOBASZ II and WOBASZ Senior study, in order to evaluate the changes in the prevalence of optimal, normal, high-normal pressure, grade 1, 2 and 3 hypertension, isolated systolic hypertension, and awareness, treatment and control of hypertension between WOBASZ Senior and WOBASZ II studies. RR value lower than 1.0 indicates, with statistical significance, a decreased prevalence, while above 1.0 - an 
increased one. A logistic regression was used to calculate the factors associated with awareness, treatment and control of hypertension in the 2007 and 2014 surveys. The statistical analysis was performed using Statistica 12.5 (StatSoft Inc., Tulsa, Oklahoma, United States).

\section{Results}

WOBASZ Senior and WOBASZ II studies included 1096 and 467 patients at the age of over 74 years, respectively. The characteristics of the study samples is shown in Tables 1 and 2 .

The mean age of participants was $79.1 \pm 3.7$ years in 2007 and significantly increased to $80.1 \pm$ \pm 4.1 years in $2014(\mathrm{p}<0.0001)$. The proportion of participants aged 75 and older rapidly increased over the 7 years, which indicative of the aging population.

The number of married seniors and education level increased significantly. The number of men who declared minimum 30-min, uninterrupted effort at least once a month, decreased significantly. SBP and DBP significantly decreased from $153.0 \pm$ $\pm 23.9 \mathrm{mmHg}$ to $142.9 \pm 22.3 \mathrm{mmHg}$ and $85.2 \pm$ $\pm 11.9 \mathrm{mmHg}$ to $78.4 \pm 11.3 \mathrm{mmHg}$, respectively, from 2007 to 2014 ( $\mathrm{p}<0.0001$ ). A significant decrease in mean SBP and DBP was observed in the all analyzed age and sex groups. There was also a significant reduction in the level of $\mathrm{TC}$ and $\mathrm{LDL}$, from $5.0 \pm 1.1 \mathrm{mmol} / \mathrm{L}$ to $4.9 \pm 1.2 \mathrm{mmol} / \mathrm{L}$ $(\mathrm{p}<0.0001)$ and from $3.4 \pm 1.0 \mathrm{mmol} / \mathrm{L}$ to $3.0 \pm$ $\pm 1.0 \mathrm{mmol} / \mathrm{L}(\mathrm{p}<0.0001)$, respectively. An increase in the mean fasting plasma glucose from $5.6 \pm$ $\pm 2.1 \mathrm{mmol} / \mathrm{L}$ to $6.0 \pm 1.5 \mathrm{mmol} / \mathrm{L}(\mathrm{p}=0.0004)$ was noted (Table 1 ). The results are presented in Table 3.

Prevalence of optimal, normal, high-normal $\mathrm{BP}$, isolated systolic hypertension and grades 1, 2 and 3 hypertension

The prevalence of optimal pressure in Polish population aged 75-99 years (after standardization for age and sex) significantly increased from 2007 to 2014 in both men and women, from $4.9 \%$ to $14.7 \%$ (RR: 3.08 ; 95\% CI: $1.81-5.26$ ) and $4.7 \%$ to $10 \%$ (RR: 2.04 ; 95\% CI: 1.19-3.5), respectively. Also, frequency of normal pressure increased from $10.3 \%$ to $15.3 \%$ (RR: 1.49 ; $95 \%$ CI: $0.94-2.35$ ) and from $8.1 \%$ to $19.7 \%$ (RR: 2.43 ; 95\% CI: $1.64-$ -3.61). There were no significant differences in the prevalence of high-normal BP, isolated systolic hypertension grade 1 hypertension and grade 2 hypertension. Frequency of grade 3 hypertension decreased from $12.7 \%$ to $6.3 \%$ (RR: 0.5 ; $95 \%$ CI:
$0.26-0.93$ ) and from $19.8 \%$ to $5.3 \%$ (RR: $0.27 ; 95 \%$ CI: 0.16-0.46) (Fig. 1; Suppl. Table 3a, b).

\section{Prevalence, awareness, treatment and control of hypertension}

Prevalence of hypertension among people included in WOBASZ Senior and WOBASZ II studies decreased from $75.4 \%$ to $71.8 \%$ (RR: $0.93 ; 95 \%$ CI: $0.8-1.09$ ) in men, and from $75.4 \%$ to $71.8 \%$ (RR: 0.93; 95\% CI: $0.8-1.09$ ) in women. Hypertension awareness was improved from $59.2 \%$ to $72.9 \%$ (RR: 1.23 ; 95\% CI: $0.97-1.56$ ) in men, and $74.8 \%$ to 93\% (RR: 1.26 ; 95\% CI: 1.01-1.58) in women. The proportion of men and women, with implemented hypertension treatment, increased from $48.4 \%$ to 61.1\% (RR: 1.26; 95\% CI: 1.01-1.58), and from $63.2 \%$ to $82.0 \%$ (RR: 1.3 ; 95\% CI: $1.1-1.53$ ), respectively. The effectiveness of the treatment (for hypotensive target $<140 / 90 \mathrm{mmHg}$ ) was improved over two-fold, there was an increase from $10.3 \%$ to 26.8\% (RR: 2.65; 95\% CI: 1.81-3.89) in men, and from $13.8 \%$ to $33.5 \%$ in women (RR: $2.44 ; 95 \% \mathrm{CI}$ : 1.81-3.3). Similarly the effectiveness of the treatment (for hypotensive target $<150 / 90 \mathrm{mmHg}$ in people $>80$ years old) was improved over two-fold from $14.5 \%$ to $32.4 \%$ (RR: 2.23 ; 95\% CI: $1.59-3.14$ ) in men, and from $18.9 \%$ to $42.0 \%$ in women (RR: 2.22; 95\% CI: 1.81-2.89).

The highest prevalence of hypertension between 2007 and 2014 was observed in people over the age of 85 . The highest awareness of hypertension was recorded in the WOBASZ Senior study in patients aged 75-79, and in the WOBASZ II study in patients between 80 and 84 years of age. Similarly, the highest percentage of patients in 2007 was treated in the population aged 75-79, and in 2014 this concerned patients at the age of 80-84. In 2007 , the best pressure control was found in patients aged $80-84$, and in 2014 in patients in $9^{\text {th }}$ and $10^{\text {th }}$ decade of life (Fig. 2; Suppl. Table 4).

A logistic regression model was performed to show how age, sex, obesity, coexisting diabetes, hyperlipidemia and other CVD, as well as the level of education, physical activity, smoking and marital status, affect an awareness, treatment and control of hypertension in WOBASZ Senior and WOBASZ II studies. Female sex, other CVD and smoking, both in 2007 and 2014, were significantly correlated with awareness, treatment and hypertension control. In the year 2007, obesity and low level of education significantly affected the awareness of the investigated disease and its treatment. Similarly, coexisting diabetes affected hypertension treatment and control. Marital status significantly 
Table 1. Characteristic of subjects in WOBASZ Senior and WOBASZ Senior II Study.

\begin{tabular}{|c|c|c|c|c|c|c|c|}
\hline & \multicolumn{3}{|c|}{ WOBASZ Senior (2005-2007) } & \multicolumn{4}{|c|}{ WOBASZ Senior II (2013-2014) } \\
\hline & $\mathbf{n}$ & $\%$ & $95 \% \mathrm{Cl}$ & $\mathbf{n}$ & $\%$ & $95 \% \mathrm{Cl}$ & $\mathbf{P}$ \\
\hline $75-79$ & 691 & 63.1 & $59.5-66.7$ & 244 & 47.8 & $41.2-54.3$ & $<0.00001$ \\
\hline Men & 370 & 66.8 & $62.1-71.6$ & 95 & 46.3 & $35.5-57.1$ & $<0.00001$ \\
\hline Women & 321 & 59.3 & $54.0-64.7$ & 149 & 48.6 & $40.4-56.9$ & 0.0310 \\
\hline $80-84$ & 306 & 28.0 & $23.0-33.0$ & 144 & 30.8 & 23.3-38.4 & 0.2633 \\
\hline Men & 130 & 23.4 & $16.1-30.7$ & 56 & 31.6 & $19.5-43.8$ & 0.0291 \\
\hline Women & 176 & 32.7 & $25.8-39.6$ & 26 & 30.3 & $20.7-40.0$ & 0.4791 \\
\hline$\geq 85$ & 95 & 8.7 & $3.0-14.3$ & 149 & 16.9 & $8.6-25.2$ & $<0.00001$ \\
\hline Men & 54 & 9.7 & $1.8-17.6$ & 88 & 14.7 & $1.1-28.3$ & 0.6500 \\
\hline \multirow[t]{2}{*}{ Women } & 41 & 7.6 & $0-15.7$ & 53 & 18.3 & 7.9-28.7 & $<0.00001$ \\
\hline & & $\begin{array}{c}\text { Age } \\
\text { standardized }\end{array}$ & $95 \% \mathrm{Cl}$ & & $\begin{array}{c}\text { Age } \\
\text { standardized }\end{array}$ & $95 \% \mathrm{Cl}$ & $\mathbf{P}$ \\
\hline Obesity & 320 & 26.4 & $23.1-29.7$ & 143 & 28.8 & 23.9-33.6 & 0.6558 \\
\hline Men & 121 & 20.3 & $16.4-24.2$ & 42 & 22.4 & $15.6-29.2$ & 0.1505 \\
\hline Women & 199 & 31.8 & $26.7-36.9$ & 101 & 32.7 & $26.2-39.3$ & 0.3992 \\
\hline Diabetes & 200 & 17.5 & $14.7-20.3$ & 100 & 21.5 & $17.1-25.8$ & 0.0194 \\
\hline Men & 92 & 15.6 & $12.1-19$ & 36 & 20.5 & $13.7-27.3$ & 0.2146 \\
\hline Women & 108 & 20.5 & $15.6-25.5$ & 64 & 22.0 & $16.4-27.6$ & 0.0657 \\
\hline Hyperlipidemia & 713 & 64.2 & $58.7-69.7$ & 302 & 64.2 & $56.7-71.6$ & 0.9012 \\
\hline Men & 340 & 59.3 & $52.5-66.2$ & 108 & 60.2 & $48.7-71.7$ & 0.7435 \\
\hline Women & 373 & 70.5 & $61.5-79.5$ & 194 & 66.8 & $57.1-76.4$ & 0.7975 \\
\hline Diagnosed CVD & 611 & 56.3 & $51.1-61.4$ & 247 & 54.0 & $47-60.9$ & 0.0084 \\
\hline Men & 288 & 52.9 & $46.2-59.5$ & 94 & 53.6 & $42.6-64.5$ & 0.5048 \\
\hline Women & 323 & 59.4 & $51.4-67.3$ & 153 & 54.3 & $45.4-63.2$ & 0.0027 \\
\hline $\begin{array}{l}\text { Education } \\
\geq 7 \text { years }\end{array}$ & 476 & 39.0 & $35-43$ & 433 & 91.9 & 83-100 & $<0.00001$ \\
\hline Men & 388 & 65.9 & $58.8-73$ & 170 & 96.1 & 81.4-100 & $<0.00001$ \\
\hline Women & 88 & 12.7 & $9.9-15.6$ & 263 & 89.3 & $78.2-100$ & $<0.00001$ \\
\hline $\begin{array}{l}\text { Physical exercise } \\
\geq 30 / \mathrm{min}\end{array}$ & 466 & 37.3 & $45.1-66.4$ & 150 & 30.5 & $25.6-35.5$ & 0.0773 \\
\hline Men & 283 & 46.1 & $40.3-51.9$ & 62 & 34.8 & $26-43.6$ & 0.0255 \\
\hline Women & 183 & 29.8 & $24.6-35$ & 88 & 27.9 & 21.9-33.8 & 0.9401 \\
\hline Smokers & 87 & 6.7 & $5.1-8.2$ & 34 & 6.8 & $4.5-9.2$ & 0.4883 \\
\hline Men & 69 & 10.8 & $8.1-13.5$ & 26 & 14.1 & 8.6-19.5 & 0.1521 \\
\hline Women & 18 & 3.0 & $1.3-4.7$ & 8 & 2.7 & $0.8-4.6$ & 0.7 \\
\hline Marital status & 295 & 28.6 & $24.8-32.5$ & 274 & 59.0 & $51.9-66.2$ & $<0.00001$ \\
\hline Men & 115 & 21.9 & $17.5-26.3$ & 90 & 51.6 & $40.8-62.4$ & 0.0004 \\
\hline Women & 180 & 36.2 & $29.5-43$ & 184 & 63.2 & $53.8-72.6$ & $<0.00001$ \\
\hline
\end{tabular}

CVD - cardiovascular disease; $\mathrm{Cl}$ - confidence interval

affected hypertension awareness in 2007. Table 4 shows factors affecting awareness, treatment and control of hypertension in 2007 and 2014 in the elderly Polish population.

\section{Discussion}

According to available research, this is the first study presenting the changes in trends over 
Table 2. Clinical characteristic of subjects who completed both the WOBASZ Senior and WOBASZ II surveys.

\begin{tabular}{|c|c|c|c|c|c|c|c|c|c|}
\hline & \multicolumn{4}{|c|}{ WOBASZ Senior (2003-2005) } & \multicolumn{4}{|c|}{$\begin{array}{c}\text { WOBASZ II (2013-2014) } \\
\text { under } 74 \text { years }\end{array}$} & \multirow[b]{2}{*}{$\mathbf{P}$} \\
\hline & $\mathbf{n}$ & Mean & SD & $95 \% \mathrm{Cl}$ & $\mathbf{n}$ & Mean & SD & $95 \% \mathrm{Cl}$ & \\
\hline \multicolumn{10}{|c|}{ Whole population } \\
\hline Age [years] & 1096 & 79.1 & 3.7 & 78.9-79.3 & 467 & 80.1 & 4.1 & 75-99 & $<0.0001$ \\
\hline SBP $[\mathrm{mmHg}]$ & 1092 & 153.0 & 23.9 & $151.6-154.4$ & 467 & 142.9 & 22.3 & $84-228.5$ & 0.20690 \\
\hline $\mathrm{DBP}[\mathrm{mmHg}]$ & 1078 & 27.9 & 5.2 & $27.6-28.2$ & 426 & 28.1 & 4.7 & $17.7-43.5$ & $<0.0001$ \\
\hline BMI $\left[\mathrm{kg} / \mathrm{m}^{2}\right]$ & 1092 & 85.2 & 11.9 & $84.5-85.9$ & 467 & 78.4 & 11.3 & $46-150$ & $<0.0001$ \\
\hline $\mathrm{TC}[\mathrm{mmol} / \mathrm{L}]$ & 929 & 5.2 & 1.1 & $5.1-5.2$ & 434 & 4.9 & 1.2 & $1.9-8.8$ & $<0.0001$ \\
\hline TG [mmol/L] & 928 & 1.3 & 0.7 & $1.3-1.4$ & 434 & 1.4 & 0.7 & $0.4-5.4$ & 0.0142 \\
\hline LDL [mmol/L] & 929 & 3.4 & 1.0 & 3.3-3.4 & 434 & 3.0 & 1.0 & $0.8-6.6$ & $<0.0001$ \\
\hline HDL [mmol/L] & 929 & 1.4 & 0.4 & $1.3-1.4$ & 434 & 1.4 & 0.4 & $0.4-2.9$ & NA \\
\hline FPG $[\mathrm{mmol} / \mathrm{L}]$ & 950 & 5.6 & 2.1 & $5.5-5.8$ & 435 & 6.0 & 1.5 & $3.7-14.6$ & 0.0004 \\
\hline \multicolumn{10}{|l|}{ Men } \\
\hline Age [years] & 555 & 79.0 & 3.9 & 78.7-79.3 & 177 & 79.9 & 4.2 & $79.3-80.6$ & 0.089 \\
\hline $\mathrm{SBP}[\mathrm{mmHg}]$ & 554 & 151.0 & 23.2 & $149.1-153$ & 177 & 141.0 & 22.3 & 137.7-144.3 & $<0.00001$ \\
\hline $\mathrm{DBP}[\mathrm{mmHg}]$ & 545 & 27.1 & 4.2 & $26.8-27.5$ & 165 & 27.3 & 4.4 & $26.6-28$ & 0.5856 \\
\hline $\mathrm{BMI}\left[\mathrm{kg} / \mathrm{m}^{2}\right]$ & 554 & 83.7 & 11.4 & $82.8-84.7$ & 177 & 77.3 & 12.9 & $75.4-79.2$ & $<0.00001$ \\
\hline TC [mmol/L] & 471 & 4.9 & 1.0 & $4.9-5$ & 169 & 4.8 & 1.3 & $4.6-5$ & 0.3053 \\
\hline TG [mmol/L] & 471 & 1.2 & 0.6 & $1.1-1.2$ & 169 & 1.4 & 0.7 & $1.3-1.5$ & 0.6658 \\
\hline LDL [mmol/L] & 471 & 3.2 & 1.0 & $3.1-3.3$ & 169 & 2.9 & 1.1 & $2.8-3.1$ & 0.0012 \\
\hline $\mathrm{HDL}$ [mmol/L] & 471 & 1.3 & 0.4 & $1.3-1.3$ & 169 & 1.3 & 0.4 & $1.3-1.4$ & ND \\
\hline $\mathrm{FPG}[\mathrm{mmol} / \mathrm{L}]$ & 481 & 5.6 & 2.1 & $5.4-5.7$ & 170 & 6.0 & 1.4 & $5.8-6.2$ & 0.0213 \\
\hline \multicolumn{10}{|l|}{ Women } \\
\hline Age [years] & 541 & 79.2 & 3.4 & 78.9-79.5 & 290 & 80.1 & 4.1 & 79.7-80.6 & 0.0008 \\
\hline $\mathrm{SBP}[\mathrm{mmHg}]$ & 538 & 154.9 & 24.5 & $152.9-157$ & 290 & 144.1 & 22.2 & $141.6-146.7$ & $<0.00001$ \\
\hline $\mathrm{DBP}[\mathrm{mmHg}]$ & 538 & 86.7 & 12.2 & $85.7-87.7$ & 290 & 79.1 & 10.1 & $77.9-80.2$ & $<0.00001$ \\
\hline BMI $\left[\mathrm{kg} / \mathrm{m}^{2}\right]$ & 533 & 28.8 & 5.9 & $28.3-29.3$ & 261 & 28.6 & 4.7 & $28-29.2$ & 0.6326 \\
\hline $\mathrm{TC}[\mathrm{mmol} / \mathrm{L}]$ & 458 & 5.4 & 1.1 & $5.3-5.5$ & 265 & 5.0 & 1.2 & $4.9-5.1$ & $<0.00001$ \\
\hline $\mathrm{TG}[\mathrm{mmol} / \mathrm{L}]$ & 457 & 1.5 & 0.7 & $1.4-1.6$ & 265 & 1.5 & 0.7 & $1.4-1.6$ & ND \\
\hline LDL [mmol/L] & 458 & 3.5 & 1.1 & $3.4-3.6$ & 265 & 3.0 & 1.0 & $2.9-3.1$ & $<0.00001$ \\
\hline HDL [mmol/L] & 458 & 1.4 & 0.4 & $1.4-1.4$ & 265 & 1.4 & 0.4 & $1.4-1.5$ & ND \\
\hline FPG [mmol/L] & 469 & 5.7 & 2.1 & $5.5-5.9$ & 265 & 6.0 & 1.6 & $5.8-6.2$ & 0.044 \\
\hline
\end{tabular}

$\mathrm{BMI}$ — body mass index; $\mathrm{Cl}$ — confidence interval; DBP — diastolic blood pressure; FPG — fasting plasma glucose; HDL — high density lipoprotein cholesterol; LDL — low density lipoprotein cholesterol; SBP — systolic blood pressure; SD — standard deviation; TC — total cholesterol; TG — triglicerydes

2007-2014, in the range of prevalence of optimal, normal, high-normal pressure, isolated systolic hypertension and grade 1 and 2 hypertension, as well as the degree of awareness, treatment and control of hypertension in the very elderly Polish population. The only Polish epidemiological study on the elderly and very elderly population involving 4950 people at the age of 65-104 years, was PolSenior study [26], carried out between 2007 and 2011. Comparing WOBASZ Senior, PolSenior and WOBASZ II studies, a gradual decrease was found in average SBP and DBP in both men and women. In these observations, the number of seniors with optimal and normal BP increased significantly, and the number of patients with grade 1 and 2 hypertension decreased. This can be explained by an increase in the number of patients treated with antihypertensive drugs, and an increase in the number of patients who managed to improve BP control. These data are consistent with the global trend for the general population, in which a decline in both SBP and DBP has been observed in recent 
Table 3. Crude mean systolic blood pressure in WOBASZ Senior and WOBASZ Senior II in population at the age 75-99.

\begin{tabular}{|c|c|c|c|c|c|c|c|c|c|}
\hline & \multicolumn{4}{|c|}{ WOBASZ Senior (2005-2007) } & \multicolumn{4}{|c|}{ WOBASZ Senior II (2013-2014) } & \multirow[b]{2}{*}{$\mathbf{P}$} \\
\hline & $\mathbf{n}$ & Mean & SD & $95 \% \mathrm{Cl}$ & $\mathbf{n}$ & Mean & SD & $95 \% \mathrm{Cl}$ & \\
\hline \multicolumn{10}{|c|}{ SYSTOLIC BLOOD PRESSURE } \\
\hline \multicolumn{10}{|c|}{ Overall } \\
\hline $75-79$ & 691 & 152.6 & 23.9 & $150.8-154.4$ & 244 & 143.2 & 22.2 & $140.4-146.0$ & $<0.00001$ \\
\hline $80-84$ & 306 & 152.6 & 23.3 & $149.1-157.2$ & 144 & 140.3 & 22.3 & $139.4-146.8$ & $<0.00001$ \\
\hline$\geq 85$ & 95 & 156.9 & 25.6 & $151.7-162.1$ & 79 & 141.8 & 22.3 & $136.8-146.8$ & 0.0001 \\
\hline Total & 1092 & 153.0 & 23.9 & $151.6-154.4$ & 467 & 142.9 & 22.3 & $140.9-145.0$ & $<0.00001$ \\
\hline \multicolumn{10}{|l|}{ Men } \\
\hline $75-79$ & 370 & 150.1 & 23.1 & $147.7-152.4$ & 95 & 140.4 & 22.1 & $135.9-144.9$ & 0.0003 \\
\hline $80-84$ & 130 & 153.2 & 23.3 & $148.8-155.7$ & 56 & 139.4 & 23.2 & $137.5-149.6$ & 0.02 \\
\hline$\geq 85$ & 54 & 152.7 & 23.4 & $146.3-159.1$ & 26 & 137.7 & 22.7 & $128.5-146.8$ & 0.082 \\
\hline Total & 554 & 151.0 & 23.2 & $149.1-153.0$ & 177 & 141.0 & 22.3 & $137.7-144.3$ & $<0.00001$ \\
\hline \multicolumn{10}{|c|}{ Women } \\
\hline $75-79$ & 321 & 155.5 & 24.5 & $152.8-158.2$ & 149 & 145.0 & 22.1 & $141.4-148.6$ & 0.0065 \\
\hline $80-84$ & 176 & 152.2 & 23.4 & $148.8-155.7$ & 88 & 141.1 & 21.8 & $138.0-147.6$ & 0.0048 \\
\hline$\geq 85$ & 41 & 162.3 & 27.5 & $153.6-171.0$ & 53 & 143.8 & 22.1 & $137.8-150.0$ & 0.0005 \\
\hline Total & 538 & 154.9 & 24.5 & $152.9-157.0$ & 290 & 144.1 & 22.2 & $141.6-146.7$ & $<0.00001$ \\
\hline \multicolumn{10}{|c|}{ DIASTOLIC BLOOD PRESSURE } \\
\hline \multicolumn{10}{|c|}{ Overall } \\
\hline $75-79$ & 691 & 85.4 & 11.9 & $84.5-86.3$ & 244 & 78.8 & 11.6 & $77.3-80.2$ & $<0.00001$ \\
\hline $80-84$ & 306 & 85.2 & 11.9 & $83.8-86.5$ & 80 & 78.2 & 12.1 & $76.4-80.1$ & $<0.00001$ \\
\hline$\geq 85$ & 95 & 84.0 & 11.8 & $81.6-86.4$ & 79 & 77.5 & 10.8 & $75.0-79.9$ & 0.0002 \\
\hline Total & 1092 & 85.2 & 11.9 & $84.5-86.0$ & 467 & 78.4 & 11.3 & $77.4-79.4$ & $<0.00001$ \\
\hline \multicolumn{10}{|l|}{ Men } \\
\hline $75-79$ & 370 & 83.6 & 11.4 & $82.4-84.8$ & 95 & 78.8 & 13.8 & $76.0-81.6$ & 0.0005 \\
\hline $80-84$ & 130 & 84.4 & 11.2 & $82.5-86.3$ & 36 & 75.5 & 12.9 & $73.6-80.0$ & 0.0001 \\
\hline$\geq 85$ & 54 & 82.9 & 11.4 & $79.7-86.0$ & 26 & 72.7 & 10.8 & $68.3-77.0$ & 0.0003 \\
\hline Total & 554 & 83.7 & 11.4 & $82.8-84.7$ & 177 & 77.3 & 12.9 & $75.4-79.2$ & $<0.00001$ \\
\hline \multicolumn{10}{|c|}{ Women } \\
\hline $75-79$ & 321 & 87.4 & 12.1 & $86.1-88.7$ & 149 & 78.7 & 9.9 & $77.1-80.3$ & $<0.00001$ \\
\hline $80-84$ & 176 & 85.7 & 12.4 & $83.9-87.6$ & 44 & 80.5 & 11.0 & $77.0-81.4$ & $<0.00001$ \\
\hline$\geq 85$ & 41 & 85.5 & 12.4 & $81.6-89.4$ & 53 & 79.8 & 10.1 & $77.0-82.6$ & 0.0159 \\
\hline Total & 538 & 86.7 & 12.2 & $85.7-87.7$ & 290 & 79.1 & 10.1 & $77.9-80.2$ & $<0.00001$ \\
\hline
\end{tabular}

$\mathrm{Cl}$ - confidence interval; SD — standard deviation

years [27]. In populations of seniors, hypertension is more common in women. This was confirmed by American (NHANES) [28] and German studies (CARLA-STUDY) [29].

Prevalence of hypertension observed in the analyzed groups of seniors participating in WOBSZ Senior and WOBASZ Senior II studies was similar to populations of developed countries of Western Europe, e.g. France and Germany (comparison of the incidence of hypertension, awareness, treatment and control is presented in Suppl. Table 5).

The prevalence of hypertension in Poland is slightly higher than in the American, Greek, Italian, Spanish and Thai populations. These studies consistently show a higher incidence of hypertension in women compared to men. A similar trend was observed in the American and German studies — higher hypertension awareness and treatment 


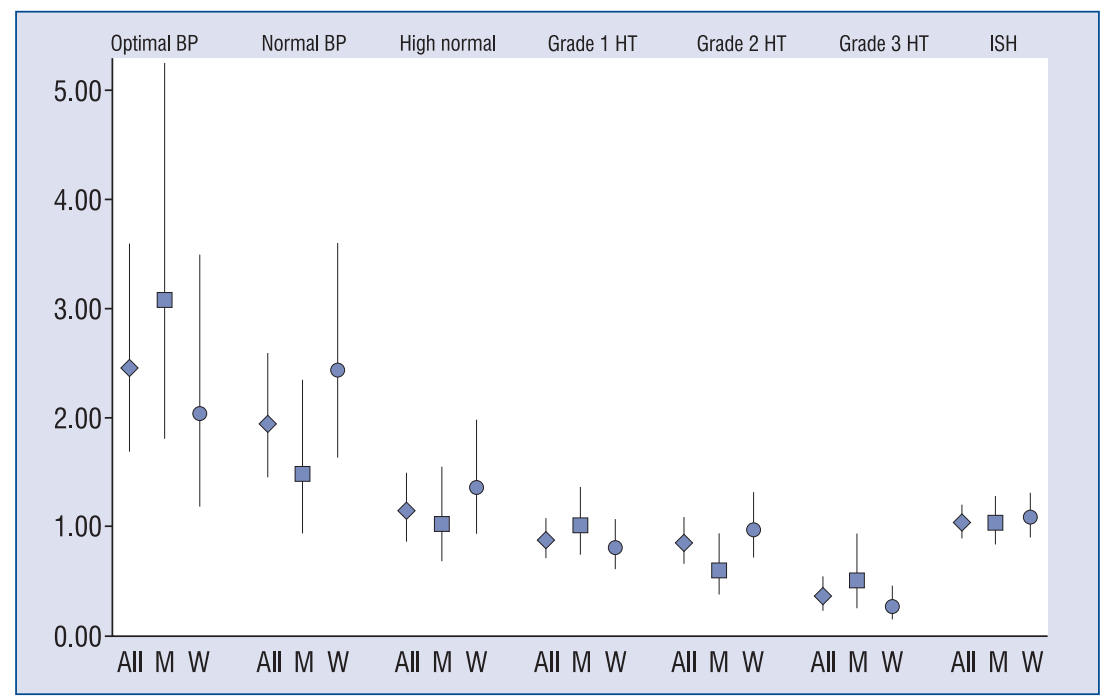

Figure 1. Changes in the prevalence of blood pressure (BP) classes i.e. optimal, normal, high normal BP, grades 1,2 and 3 hypertension (HT) and isolated systolic hypertension (ISH) in a subsample at ages restricted to 75-99 years in WOBASZ Senior (2005-2007) and WOBASZ II (2013-2014); M - men; W - women.

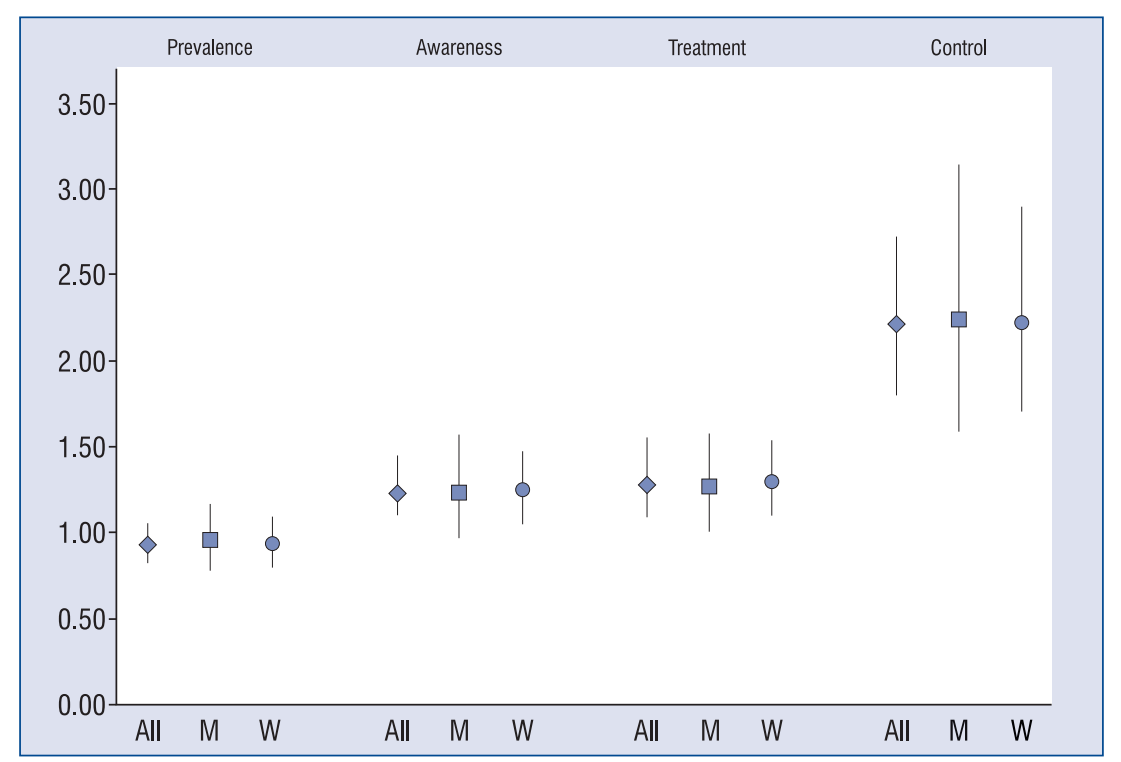

Figure 2. Changes in the hypertension prevalence, awareness, treatment, and control of blood pressure in a subsample at ages restricted to 75-99 years in WOBASZ Senior (2005-2007) and WOBASZ II (2013-2014); M - men; W - women.

were observed in more women than in men. An effectiveness of hypertension treatment is higher in women than in men, regardless of the examined senior population. Comparing the WOBASZ studies to another Polish POLSENIOR study, it was noted that an increase in hypertension prevalence in Polish seniors population with a concurrent increase in the frequency of its awareness. Also observed was a systematic increase in the number of patients with implemented hypertension treatment, with simultaneous improvement in its effectiveness. The control of arterial pressure in the elderly is important because, as recently described by Piotrowicz et al. [30], it may correlate with mood disorders and cognitive impairment.

While the awareness and frequency of hypertension treatment in the Polish senior population, which is similar to values observed in the 





inhabitants of developed countries in America and Western Europe, the pressure control is over two-fold worse.

Potential impact of the 2017 ACC/AHA guidelines on prevention and treatment of hypertension in the Polish population needs to be further evaluated in future. The analysis of epidemiological data on the American population has shown that a percentage of American adults meeting the definition for hypertension according to the $2017 \mathrm{ACC} /$ /AHA guideline [31] and the JNC7 [32] guideline based on the 2011-2014 NHANES in people over 75 years old was $82.3 \%$ and $75.1 \%$, respectively. A percentage of American adults with SBP of 130 to $139 \mathrm{mmHg}$ or DBP of 80 to $89 \mathrm{~mm} \mathrm{Hg}$ are recommended for antihypertensive medication according to the $2017 \mathrm{ACC} / \mathrm{AHA}$ guideline in people over 75 was $100 \%$ [33].

A significant decline in physical activity among the seniors over less than a decade can be considered as a worrisome tendency. Also, a significant increase in hyperlipidemia prevalence in the Polish elderly examined in WOBASZ Senior and WOBASZ II studies is an issue. An increase in the incidence of obesity and diabetes also raises concern. Similar changes, although smaller, were also observed in the Polish population aged 20 -75 years in the decade 2003/4-2013/14 [34-36] and in the study by Jarosz et al. [37]. It was reported in a number of studies, similarly to the present observations, that females significantly affect an increased hypertension awareness, treatment and control [38-41]. A similar relationship was also confirmed for obesity. This is consistent with a study conducted by $\mathrm{He}$ et al. [42]. In turn, another study demonstrated that obesity was significantly related to higher awareness and worse pressure control [38-40, 43]. In WOBASZ Senior and WOBASZ Senior II studies, smoking significantly affected lower awareness and treatment frequency and blood pressure control. This is consistent with other observations [44-46]. The coexistence of other CVD and diabetes significantly increased the awareness of hypertension in the Polish study conducted among seniors. Comparable results were obtained in a Chinese population over the age of 60 [38]. The relationship between education level and hypertension awareness, treatment and control varies depending on the population analyzed. WOBASZ Senior study demonstrated a significant relationship between low levels of education and lower awareness and lower incidence of hypotensive treatment, as in the Chinese population, the study conducted by Wu et al. [40], Tian et al. [45], and Chiu [46]. In turn, higher education in the study by Wang et al. [47] was associated with lower awareness and less frequent treatment.

One, strength of the WOBASZ studies is the large group of people examined - of 2007, $\mathrm{n}=1096$ and of 2013/14, $n=461$. Second, sampling was performed in three stages, stratified according to voivodeship, type of community, and gender. The findings in the present study are subjected to some limitations. First, the study design assumed BP measurements on only one visit. Therefore, the results may overestimate the prevalence of hypertension and underestimate of its control. Second, because the described categories of BP concerned the whole population, including those treated, obtained rates of optimal, correct and high optimal pressure could be overestimated.

\section{Conclusions}

In the years 2007-2014, SBP and DBP significantly decreased in people aged 75 years and older. Prevalence of hypertension in the Polish senior population slightly decreased, while awareness, frequency of treatment and disease control improved. Despite a significant increase in hypertension control in Poland in the elderly, during the 7 -year observation period, approx. $70 \%$ of seniors present poorly in controlled pressure.

This results should mobilize both primary care physicians and specialists to increase efforts to intensify antihypertensive treatment in this group of patients.

\section{Acknowledgements}

On behalf of the Steering Committee of the WOBASZ Program, we express heartfelt thanks for the participation to all of our co-workers from the research teams in 6 academic centers as well as nurses, doctors and analysts from local research centers in 16 provinces of this study.

Special thanks to Stanisław Paradowski for his help in the statistical calculations.

Funding: WOBASZ II project was financed from the financial resources at the disposal of the Minister of Health within the framework of the health program entitled: National Program of Equalization the Accessibility to Cardiovascular Disease Prevention and Treatment for 2010-2012 POLKARD - goal: Analyses and epidemiology - "Monitoring of the epidemiological situation in Poland in the field of cardiovascular diseases". 
Conflict of interest: Andrzej Pająk declares personal fees from Amgen and Sanofi not related to the submitted work.

\section{References}

1. http://ec.europa.eu/eurostat/statistics-explained/index.php/Population_structure_and_ageing.

2. http://stat.gov.pl/cps/rde/xbcr/gus/L_ludnosc_stan_struktura_2007.zip (access 9-01-2018).

3. $\quad$ stat.gov.pl/download/gfx/portalinformacyjny/pl/defaultaktualnosci/5468/6/17/1/ludnosc_stan_i_struk_lud_oraz_ruch_natur_w_ przekroju_teryt_w_2014_stan_31_xii.pdf (access 9-01-2018).

4. http://stat.gov.pl/download/gfx/portalinformacyjny/pl/defaultaktualnosci/5468/24/1/1/ludnosc_w_wieku_60._struktura_ demograficzna_i_zdrowie.pdf (access 9-01-2018).

5. stat.gov.pl/download/gfx/portalinformacyjny/pl/defaultaktualnosci/5468/18/1/1/ludnosc_w_starszym_wieku.pdf (access 9-012018).

6. Lewington S, Clarke R, Qizilbash N, et al. Prospective Studies Collaboration. Age-specific relevance of usual blood pressure to vascular mortality: a meta-analysis of individual data for one million adults in 61 prospective studies. Lancet. 2002; 360(9349): 1903-1913, indexed in Pubmed: 12493255.

7. Staessen JA, Gasowski J, Wang JG, et al. Risks of untreated and treated isolated systolic hypertension in the elderly: metaanalysis of outcome trials. Lancet. 2000; 355(9207): 865-872, indexed in Pubmed: 10752701.

8. Bejan-Angoulvant T, Saadatian-Elahi M, Wright JM, et al. Treatment of hypertension in patients 80 years and older: the lower the better? A meta-analysis of randomized controlled trials. J Hypertens. 2010; 28(7): 1366-1372, doi: 10.1097/ HJH.0b013e328339f9c5, indexed in Pubmed: 20574244.

9. Kąkol M, Zdrojewski T, et al. Kozicka Kąkol Prevalence, awareness and treatment efficacy of arterial hypertension in elderly in and: estimates based on a representative survey. Geront Pol. 1999; 2: 23-28.

10. Antikainen RL, Kastarinen MJ, Jousilahti P, et al. Despite evidence-based guidelines, systolic blood pressure remains inadequately controlled in older hypertensive adults. J Hum Hypertens. 2010; 24(7): 439-446, doi: 10.1038/jhh.2009.85, indexed in Pubmed: 19890369.

11. Psaltopoulou T, Orfanos P, Naska A, et al. Prevalence, awareness, treatment and control of hypertension in a general population sample of 26,913 adults in the Greek EPIC study. Int J Epidemiol. 2004; 33(6): 1345-1352, doi: 10.1093/ije/dyh249, indexed in Pubmed: 15218014.

12. Joffres M, Falaschetti E, Gillespie C, et al. Hypertension prevalence, awareness, treatment and control in national surveys from England, the USA and Canada, and correlation with stroke and ischaemic heart disease mortality: a cross-sectional study. BMJ Open. 2013; 3(8): e003423, doi: 10.1136/bmjopen-2013-003423, indexed in Pubmed: 23996822.

13. Falaschetti E, Mindell J, Knott C, et al. Hypertension management in England: a serial cross-sectional study from 1994 to 2011. Lancet. 2014; 383(9932): 1912-1919, doi: 10.1016/S01406736(14)60688-7, indexed in Pubmed: 24881995.

14. Diederichs C, Neuhauser H. Regional variations in hypertension prevalence and management in Germany: results from the German Health Interview and Examination Survey
(DEGS1). J Hypertens. 2014; 32(7): 1405-1414, doi: 10.1097/ HJH.0000000000000211, indexed in Pubmed: 24834980.

15. Tykarski A, Posadzy-Małaczyńska A, Wyrzykowski B, et al. [Prevalence of hypertension and effectiveness of its treatment in adult residents of our country. Results of the WOBASZ program]. Kardiol Pol. 2005; 63(6 Suppl 4): S614-S619, indexed in Pubmed: 20527432.

16. Zdrojewski Ł, Zdrojewski T, Rutkowski M, et al. Prevalence and control of cardiovascular risk factors in Poland. Assumptions and objectives of the NATPOL 2011 Survey. Kardiol Pol. 2013; 71(4): 381-392, doi: 10.5603/KP.2013.0066, indexed in Pubmed: 23788344.

17. Zdrojewski T, Wizner B, Więcek A, et al. Prevalence, awareness, and control of hypertension in elderly and very elderly in Poland: results of a cross-sectional representative survey. J Hypertens. 2016; 34(3): 532-8; discussion 538, doi: 10.1097/ HJH.0000000000000823, indexed in Pubmed: 26771343.

18. Zdrojewski T, Broda G, Piotrowski W, et al. Badanie WOBASZ Senior - ocena epidemiologii czynników ryzyka chorób serca i naczyń u starszych Polaków. In: Kopeć G, Jankowski P, Pająk A, Drygas W. Epidemiologia i prewencja chorób układu krążenia. Medycyna Praktyczna, Kraków. 2015: 93-99.

19. Drygas W, Niklas AA, Piwońska A, et al. Multi-centre National Population Health Examination Survey (WOBASZ II study): assumptions, methods, and implementation. Kardiol Pol. 2016; 74(7): 681-690, doi: 10.5603/KP.a2015.0235, indexed in Pubmed: 26620680 .

20. Rywik S, Kupść W, Piotrowski W, et al. Programu WOBASZ. [Multicenter national Polish population health status tests: WOBASZ project. Establishment of methods and logistics]. Kardiol Pol. 2005; 63(6 Suppl 4): S605-S613, indexed in Pubmed: 20527431.

21. http://www.ehes.info/manuals/EHES_manual/EHES_manual. htm (access 9-01-2018).

22. Mancia G, Fagard R, Narkiewicz K, et al. ESH/ESC Task Force for the Management of Arterial Hypertension, Task Force Members. $2013 \mathrm{ESH} / \mathrm{ESC}$ Guidelines for the management of arterial hypertension: the Task Force for the management of arterial hypertension of the European Society of Hypertension (ESH) and of the European Society of Cardiology (ESC). J Hypertens. 2013; 31(7): 1281-1357, doi: 10.1097/01.hjh.0000431740.32696.cc, indexed in Pubmed: 23817082.

23. Gee ME, Campbell N, Sarrafzadegan N, et al. Standards for the uniform reporting of hypertension in adults using population survey data: recommendations from the World Hypertension League Expert Committee. J Clin Hypertens (Greenwich). 2014; 16(11): 773-781, doi: 10.1111/jch.12387, indexed in Pubmed: 25157607.

24. Morris JA, Gardner MJ. Calculating confidence intervals for relative risks (odds ratios) and standardized. ratios and rates. Br Med J. 1988; 296(7 May): 1313-1316.

25. http://stat.gov.pl/download/gfx/portalinformacyjny/pl/defaultaktualnosci/5468/12/5/1/podstawowe_informacje_o_rozwoju_demograficznym_polski_do_2014.pdf (access 9-01-2018).

26. Bledowski P, Mossakowska M, Chudek J, et al. Medical, psychological and socioeconomic aspects of aging in Poland: assumptions and objectives of the PolSenior project. Exp Gerontol. 2011; 46(12): 1003-1009, doi: 10.1016/j.exger.2011.09.006, indexed in Pubmed: 21979452.

27. Danaei G, Finucane MM, Lin JK, et al. Global Burden of Metabolic Risk Factors of Chronic Diseases Collaborating Group (Blood 
Pressure). National, regional, and global trends in systolic blood pressure since 1980: systematic analysis of health examination surveys and epidemiological studies with 786 country-years and $5 \cdot 4$ million participants. Lancet. 2011; 377(9765): 568-577, doi: 10.1016/ S0140-6736(10)62036-3, indexed in Pubmed: 21295844.

28. McDonald M, Hertz RP, Unger AN, et al. Prevalence, awareness, and management of hypertension, dyslipidemia, and diabetes among United States adults aged 65 and older. J Gerontol A Biol Sci Med Sci. 2009; 64(2): 256-263, doi: 10.1093/gerona/gln016, indexed in Pubmed: 19181717.

29. Lacruz ME, Kluttig A, Hartwig S, et al. Prevalence and Incidence of Hypertension in the General Adult Population: Results of the CARLA-Cohort Study. Medicine (Baltimore). 2015; 94(22): e952, doi: 10.1097/MD.0000000000000952, indexed in Pubmed: 26039136.

30. Piotrowicz K, Prejbisz A, Klocek M, et al. Subclinical mood and cognition impairments and blood pressure control in a large cohort of elderly hypertensives. J Am Med Dir Assoc. 2016; 17(9): 864.e17-864.e22, doi: 10.1016/j.jamda.2016.06.021, indexed in Pubmed: 27502451.

31. Whelton PK, Carey RM, Aronow WS, et al. 2017 ACC/AHA/ /AAPA/ABC/ACPM/AGS/APhA/ASH/ASPC/NMA/PCNA Guideline for the Prevention, Detection, Evaluation, and Management of High Blood Pressure in Adults: A Report of the American College of Cardiology/American Heart Association Task Force on Clinical Practice Guidelines. Hypertension. 2017 [Epub ahead of print], doi: 10.1161/HYP.0000000000000065, indexed in Pubmed: 29133356.

32. Chobanian AV, Bakris GL, Black HR, et al. National Heart, Lung, and Blood Institute Joint National Committee on Prevention, Detection, Evaluation, and Treatment of High Blood Pressure, National High Blood Pressure Education Program Coordinating Committee. The Seventh Report of the Joint National Committee on Prevention, Detection, Evaluation, and Treatment of High Blood Pressure: the JNC 7 report. JAMA. 2003; 289(19): 2560-2572, doi: 10.1001/jama.289.19.2560, indexed in Pubmed: 12748199.

33. Muntner P, Carey RM, Gidding S, et al. Potential US Population Impact of the 2017 ACC/AHA High Blood Pressure Guideline. Circulation. 2018; 137(2): 109-118, doi: 10.1161/CIRCULATIONAHA.117.032582, indexed in Pubmed: 29133599.

34. Stepaniak U, Micek A, Waśkiewicz A, et al. Prevalence of general and abdominal obesity and overweight among adults in Poland. Results of the WOBASZ II study (2013-2014) and comparison with the WOBASZ study (2003-2005). Pol Arch Med Wewn. 2016; 126(9): 662-671, doi: 10.20452/pamw.3499, indexed in Pubmed: 27535012.

35. Kwaśniewska M, Pikala M, Bielecki W, et al. Ten-Year Changes in the Prevalence and Socio-Demographic Determinants of Physical Activity among Polish Adults Aged 20 to 74 Years. Results of the National Multicenter Health Surveys WOBASZ (2003-2005) and WOBASZ II (2013-2014). PLoS One. 2016; 11(6): e0156766, doi: 10.1371/journal.pone.0156766, indexed in Pubmed: 27272130.

36. Pająk A, Szafraniec K, Polak M, et al. Changes in the prevalence, treatment, and control of hypercholesterolemia and other dys- lipidemias over 10 years in Poland: the WOBASZ study. Pol Arch Med Wewn. 2016; 126(9): 642-652, doi: 10.20452/pamw.3464, indexed in Pubmed: 27452484.

37. Jarosz M, Wolańska D, Stolińska H, et al. Nutrition and lifestyle in patients pharmacologically treated due to hypertensionally treated due to hypertension. Cardiol J. 2016; 23(5): 491-496, doi: 10.5603/CJ.a2016.0049, indexed in Pubmed: 27439369.

38. Wu L, He Y, Jiang B, et al. Trends in prevalence, awareness, treatment and control of hypertension during 2001-2010 in an urban elderly population of china. PLoS One. 2015; 10(8): e0132814, doi: 10.1371/journal.pone.0132814, indexed in Pubmed: 26241049.

39. Tian S, Dong GH, Wang Da, et al. Prevalence, awareness, treatment, control, and risk factors associated with hypertension in urban adults from 33 communities of China: the CHPSNE study. J Hypertens. 2011; 29(7): 1303-1310, doi: 10.1097/ HJH.0b013e328347f79e, indexed in Pubmed: 21558952.

40. Wu Yi, Tai ES, Heng D, et al. Risk factors associated with hypertension awareness, treatment, and control in a multi-ethnic Asian population. J Hypertens. 2009; 27(1): 190-197, indexed in Pubmed: 19145784.

41. Agyemang C, Bruijnzeels MA, Owusu-Dabo E. Factors associated with hypertension awareness, treatment, and control in Ghana, West Africa. J Hum Hypertens. 2006; 20(1): 67-71, doi: 10.1038/sj.jhh.1001923, indexed in Pubmed: 16121199.

42. He J, Muntner P, Chen J, et al. Factors associated with hypertension control in the general population of the United States. Arch Intern Med. 2002; 162(9): 1051-1058, indexed in Pubmed: 11996617.

43. Chen R, Tunstall-Pedoe H, Morrison C, et al. Trends and social factors in blood pressure control in Scottish MONICA surveys 1986-1995: the rule of halves revisited. J Hum Hypertens. 2003; 17(11): 751-759, doi: 10.1038/sj.jhh.1001612, indexed in Pubmed: 14578914 .

44. Agyemang C, van Valkengoed I, Koopmans R, et al. Factors associated with hypertension awareness, treatment and control among ethnic groups in Amsterdam, the Netherlands: the SUNSET study. J Hum Hypertens. 2006; 20(11): 874-881, doi: 10.1038/sj.jhh.1002073, indexed in Pubmed: 16929341.

45. Tian S, Dong GH, Wang Da, et al. Factors associated with prevalence, awareness, treatment and control of hypertension in urban adults from 33 communities in China: the CHPSNE Study. Hypertens Res. 2011; 34(10): 1087-1092, doi: 10.1038/hr.2011.99, indexed in Pubmed: 21775998.

46. Chiu YH, Wu SC, Tseng CD, et al. Progression of pre-hypertension, stage 1 and 2 hypertension (JNC 7): a populationbased study in Keelung, Taiwan (Keelung Community-based Integrated Screening No. 9). J Hypertens. 2006; 24(5): 821-828, doi: 10.1097/01.hjh.0000222750.82820.19, indexed in Pubmed: 16612242.

47. Wang H, Zhang X, Zhang J, et al. Factors associated with prevalence, awareness, treatment and control of hypertension among adults in Southern China: a community-based, cross-sectional survey. PLoS One. 2013; 8(5): e62469, doi: 10.1371/journal. pone.0062469, indexed in Pubmed: 23671599. 